\title{
An Evaluation of Structural Model for Independent Learning Through Connectivism Theory and Web 2.0 Towards Students' Achievement
}

\author{
Zulkifley Mohamed \\ Sultan Idris Education University \\ Tanjung Malim, Perak, Malaysia; \\ zulkifley@fsmt.upsi.edu.my
}

\author{
Nor Hasbiah Ubaidullah \\ Sultan Idris Education University \\ Tanjung Malim, Perak, Malaysia \\ hasbiah@fskik.upsi.edu.my
}

\author{
Siti Ilyana Mohd Yusof \\ Aminuddin Baki Institute \\ GentingHighlands,Pahang; \\ sitiilyana@iab.edu.my
}

\begin{abstract}
The purpose of the study was to evaluate an independent learning measurement model based on connectivism theory and Web 2.0 learning tool. The quantitative method was utilised in this study. The data were collected using connectivism and Web 2.0 learning tool instruments among students of Two Year Programme in one of the matriculation colleges in Malaysia. For the purpose of sampling, the cluster sampling was utilised. In this study, the research model was evaluated using a two-step process, those were the evaluation of the measurement model and the evaluation of the structural model. In general, the purpose of model evaluation is to determine whether both measurement and structural model fulfill the quality criteria for empirical work. The findings revealed that there were significant correlationsbetween connectivism theory and Web 2.0 learning tool towards students' achievement in the structural model. The study also showed that the students' achievement was attributed by the principles of connectivism theory and Web 2.0 as a learning tool. In conclusion, this study had successfully evaluated an independent learning model based on connectivism theory and Web 2.0 learning tool with the implementing of Partial Least SquaresStructural Equation Modelling. This study implied that apart from others factor, connectivism theory and Web 2.0 learning tool are also contributed a different perspective to the process of students' learning.
\end{abstract}

Keywords: connectivism, students' learning, web 2.0 learning tool

\section{INTRODUCTION}

Students in higher education learning environments will prepare for the future when they become self-directed learners and more motivated by learning than performance [2]. In the face of new generations of learners with ever-broadening demands on their learning, faculty wishes to provide their students with tools that will serve them in a world driven by global competition that invoke structural change in their pedagogy [2]. In parallel, the current situation has triggered educational scientists to search for new learning theories [11] which aim to explain the dynamics of recent teaching and learning processes.

One form of a new learning theory other than the commonly recognised ones as in behaviourism, cognitivism, and constructivism is connectivism. Connectivism theory emphasises on learning networks and their established connections among members. It seems that Social Networking Site (SNS) structures could provide a new platform for comprehending and implementing this learning theory. In order to take advantage of new premises regarding connectivism,
Facebook is the most well-known SNS that could certainly recommend a field of implementation where billions of people attached to each other in its highly networked body [15].

Connectivism theory has demonstrated that on a connected network, learners increase their capacities, performances, and levels of knowledge while creating and reforming the information. In that sense, SNSs comprising already linked members in their innate technologies have a superior potential to enrich learners' current knowledge, skills, and abilities. Connectivism could assist different researchers to explain the underlying reasons of change in the learners' current situation as a result of their interaction on SNSs [15]. Connectivism also enlightened that SNSs are platforms which could improve instructional processes for both learners and educators.

Connectivism is a relatively new theory of learning where scholars are conducting research in order to realise its implications to the field of education. SNS is also comparatively new tools as instructional platforms. Therefore, this study was undertaken to develop and evaluate an independent learning (IL) model by examining these two innovative concepts that require more elaboration for comprehending their effects for educational processes. This paper focuses on the evaluation of a model of IL with Facebook adoption using connectivism theoretical lens which is diversity, autonomy, interactivity, and openness through Partial Least Squares-Structural Equation Modeling (PLSSEM)as Facebook is one of the famous learning tools utilised by students in Malaysia matriculations.

\section{METHODS}

In terms of structural model evaluation, the PLS-SEM main objective is to test or predict the theoretical model that has been suggested based on the literature and not to test which alternate model fits the data better [5]. The residuals on manifest and latent variables are correlated in PLS-SEM; thus allowing PLS-SEM to estimate [10]. For this study, the research model is assessed using a two-step process: (i) the evaluation of the measurement model and (ii) the evaluation of the structural model. In general, the purpose of model evaluation is to determine whether both measurement and structural model fulfill the quality criteria for empirical work [16]. 


\section{Structural Model}

Validating the structural model can help the researcher to evaluate systematically whether the hypotheses expressed by the structural model are supported by the data [16]. The structural model can only be analysed after the measurement model has been validated successfully. In PLS-SEM, a structural model can be evaluated using coefficient of determination $\left(R^{2}\right)$, and path coefficients.

The first important criterion for assessing the PLSSEM structural model is to evaluate each endogenous latent variable coefficient of determination $\left(R^{2}\right)$. $R^{2}$ measures the relationship of a latent variableexplained variance to its total variance. According to [12], a value of
$R^{2}$ around 0.67 is considered substantial, values around 0.333 are average, and values of 0.19 and lower are considered weak.

While by examining the path coefficient value, a researcher is able to know the strength of the relationship between two latent variables. To examine the relationship between two latent variables, the researcher should check the path coefficients, algebraic sign, magnitude, and significance. According to [7], the path coefficients should exceed 0.100 to account for a certain impact within the model and be significant at least at the 0.05 level. Table 1 summarised the guidelines to validate the structural model.

Table 1: Summaries of Validity Guidelines for Evaluation of Structural Model

\begin{tabular}{lll}
\hline Validity Type & Criterion/Literature & Guideline \\
\hline Coefficient of determination $\left(R^{2}\right)$ - Chin & 0.67 - substantial \\
& $(1998 \mathrm{~b})$ & 0.333 - moderate \\
& 0.190 - weak
\end{tabular}

Model validity

Path coefficient - Huber et al. (2007)
Path coefficient must be at least 0.100 and at a significance level of at least 0.05 .
Therefore, in this study the structural model is evaluated using the following test:

i. Coefficient of determination must be larger than 0.19 .

ii. Path coefficient between latent variables must be at least 0.1 , follow the correct algebraic sign (in the case of this study - positive) and significant (at least 0.05).

\section{Coefficient of Determination $\left(R^{2}\right)$}

The $R^{2}$ value indicates the amount of variance in dependent variables that is explained by the independent variables. [4]Emphasised that acceptable values of $R^{2}$ depends on the specific research discipline as well as on the individual study. As a consequence for model estimation, [13] proposed that $R^{2}$ values of $0.15,0.34$, and 0.46 can be as a rule of thumb in empirical studies related to information systems in general and Web 2.0 applications in particular, interpreted as weak, moderate, and substantial respectively. Thus, a larger $R^{2}$ value increases the predictive ability of the structural model.

\section{Path Coefficients}

Within the structural model, each path connecting two latent variables represented a hypothesis. The structural model and the hypotheses were tested by examining the path coefficients' statistical significance and magnitudes. Based on the analysis conducted on the structural model, it allows the researcher to confirm or disconfirm each hypothesis as well as understand the relationship between the latent variables.

The relationships between the latent variables were examined by using the SmartPLS algorithm output. However, in SmartPLS in order to test the significance level, $t$-statistics for all paths are generated using the SmartPLS bootstrapping function. Before the relationships between latent variables were examined, the correlation analysis will be conducted to determine the strength of relationship between these variables. The magnitude of a path coefficient represents the strength of the direct effect. The magnitude of a path coefficient carries meaning only if the path coefficient is statistically significant. In this study, path coefficient values close to 0.5 or greater were interpreted as corresponding to large effect sizes, values around 0.3 were interpreted as corresponding to medium effect sizes, and values near and below 0.1 as corresponding to small effect sizes. These path coefficient interpretations are evaluated. If the result indicates a significant correlation, then the study will proceed to examine the relationships among the hypothesised latent variables.

\section{RESULTS AND DISCUSSION}

The following subsections discuss the tests used to evaluate the validity of the structural model for this study. The validity of the structural model is evaluated using the coefficient of determination $\left(R^{2}\right)$ and path coefficients.

\section{Coefficient of Determination $\left(R^{2}\right)$}

In this study, PLS-SEM algorithm function is used to obtain the $R^{2}$ values, while the smartPLS bootstrapping function is used to generate the $t$-statistic values and for this study, it generated 5000 samples from 81 cases.

As presented in Figure 1, the analysis of $R^{2}$ revealed that $94.7 \%$ of variance in autonomy was explained by Web $2.0,98.0 \%$ of variance in diversity was explained by Web 2.0, interactivity and openness while $96.4 \%$ of variance in interactivity was explained by Web 2.0 and openness. On the other hand, $94.2 \%$ of variance in openness was explained by Web 2.0 and $93.8 \%$ of variance in students' achievement was explained by Web 2.0, autonomy, diversity, interactivity, and openness. Thus, the findings of the structural model support and are 
in line with recent literature that emphasised connectivism core principles and relations. The results estimated using
PLS-SEM for the structural model are displayed in Figure 1 and $R^{2}$ values of the structural model are presented in

Table 2.

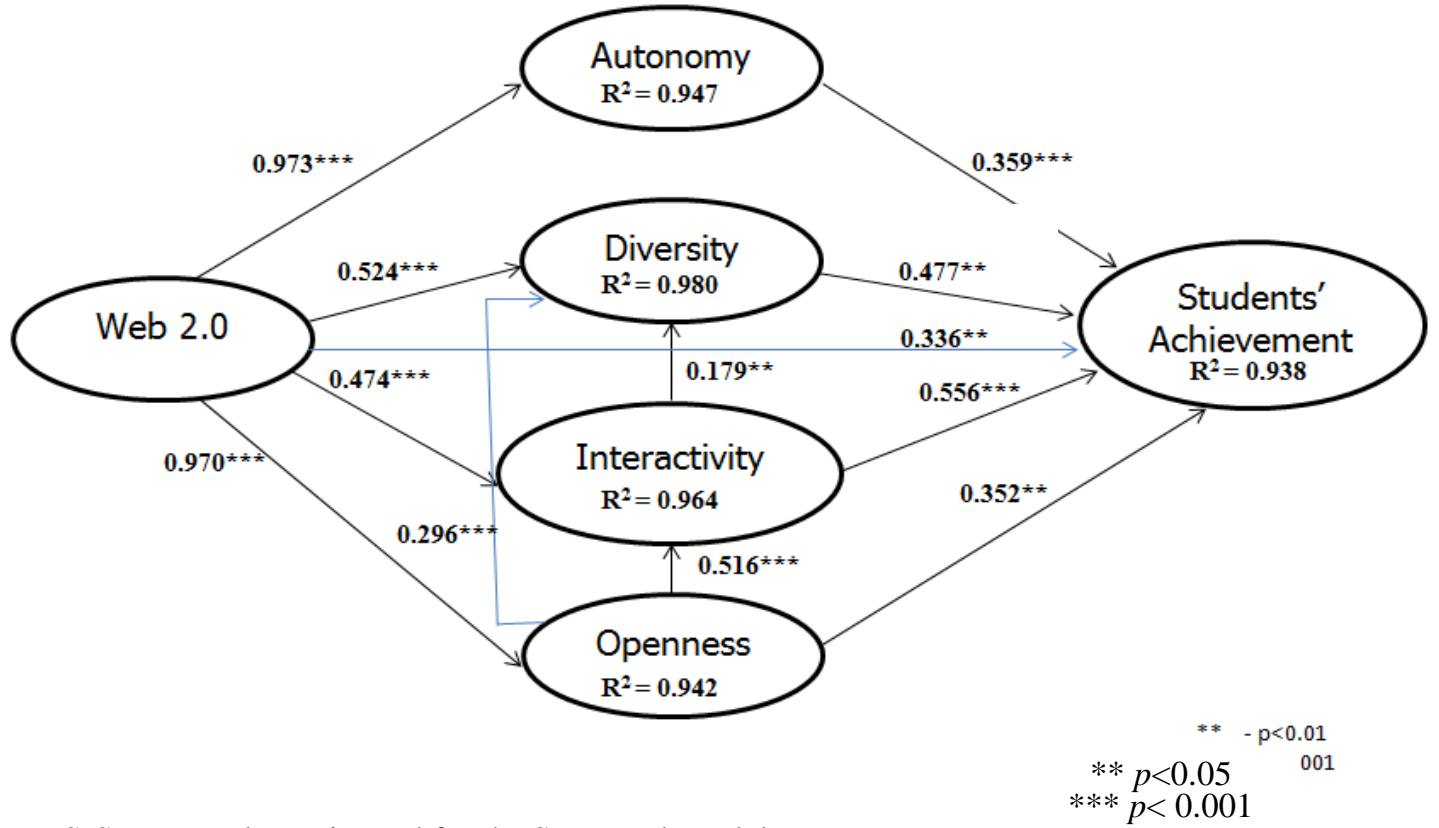

Figure 1: PLS-SEM Results Estimated for the Structural Model 
Table 2: $R^{2}$ Values of the Endogenous Construct

\begin{tabular}{|c|c|c|c|c|c|c|c|c|}
\hline Endogenous Construct & \multicolumn{2}{|l|}{$R^{2}$} & \multicolumn{2}{|c|}{ (Sample mean) } & \multicolumn{2}{|c|}{ Standard deviation } & $t$-statistic & $p$ values \\
\hline Autonomy & 0.947 & & \multicolumn{2}{|c|}{0.947} & \multicolumn{2}{|c|}{0.008} & 116.293 & $<0.001$ \\
\hline Diversity & 0.980 & & \multicolumn{2}{|l|}{0.981} & \multicolumn{2}{|l|}{0.003} & 326.36 & $<0.001$ \\
\hline Interactivity & 0.964 & & \multicolumn{2}{|l|}{0.965} & \multicolumn{2}{|l|}{0.008} & 118.882 & $<0.001$ \\
\hline Openness & 0.942 & & \multicolumn{2}{|l|}{0.941} & \multicolumn{2}{|l|}{0.009} & 101.259 & $<0.001$ \\
\hline Students' Achievement & 0.938 & & \multicolumn{2}{|c|}{0.941} & \multicolumn{2}{|l|}{0.011} & 82.762 & $<0.001$ \\
\hline \multicolumn{3}{|c|}{$\begin{array}{l}\text { In summary, the first criterion in evaluating the } \\
\text { structural model has been satisfied by determining the } R^{2} \\
\text { values for all endogenous constructs. All dependent } \\
\text { constructs have recorded strong } R^{2} \text { values overall and in } \\
\text { fact, it can be seen that from the table that diversity has } \\
\text { the strongest } R^{2} \text { values among other constructs when the } \\
\text { construct is explained } 98 \% \text { by all other constructs in the } \\
\text { model. The next section describes the analysis to test the } \\
\text { second criterion which is to determine the significance of } \\
\text { the path coefficient by employing the bootstrapping } \\
\text { procedure. }\end{array}$} & \multicolumn{6}{|c|}{$\begin{array}{l}\text { Before the hypothesis path coefficients are examined, } \\
\text { the study performed the analysis of correlation among the } \\
\text { latent variables. Table } 3 \text { lists down the correlation } \\
\text { coefficient among the latent variables. The analysis of } \\
\text { correlation among hypothesis latent variables indicates } \\
\text { that there were a significant correlation among all the } \\
\text { latent variables in structural model. }\end{array}$} \\
\hline \multicolumn{9}{|c|}{ Table 3: Correlations between Latent Variables } \\
\hline (1) Autonomy & & 0.968 & 0.951 & 0.945 & 0.951 & 0.973 & & \\
\hline (2) Diversity & 0.968 & & 0.977 & 0.978 & 0.956 & 0.985 & & \\
\hline (3) Interactivity & 0.951 & 0.977 & & 0.975 & 0.922 & 0.974 & & \\
\hline (4) Openness & 0.945 & 0.978 & 0.975 & & 0.942 & 0.970 & & \\
\hline (5) Students' Achievement & 0.951 & 0.956 & 0.922 & 0.942 & & 0.955 & & \\
\hline (6) Web 2.0 & 0.973 & 0.985 & 0.974 & 0.970 & 0.955 & & & \\
\hline
\end{tabular}

Note: All the coefficient correlations are significant at 5\% level.

The relationship between latent variables and all the hypothesised path were examined through its path coefficient, $t$-statistic, and $p$ value that were shown in Table 4. The hypothesised relationships were accepted or rejected, and characterised as weak or strong based on the algebraic signs, magnitudes, and statistical significance of the corresponding path coefficients. A path coefficient's magnitude indicates the strength of the relationship between the variables. The resulting $p$ values were interpreted as follows: (i) $p<0.05$ indicates a statistically significant relationship; (ii) $p<0.01$ indicates highly statistically significant relationship; and (iii) $p<0.001$ indicates very highly statistically significant relationship.

Table 4: Path Coefficient, $t$-statistic, and $p$ value

\begin{tabular}{lccc}
\hline Path & Path Coefficient & $t$-statistic & $p$ value \\
\hline Autonomy -> Students' Achievement & 0.359 & 2.354 & 0.019 \\
Diversity -> Students' Achievement & 0.477 & 2.418 & 0.016 \\
Interactivity -> Diversity & 0.179 & 2.099 & 0.036 \\
Interactivity -> Students' Achievement & 0.556 & 3.513 & $<0.001$ \\
Openness -> Diversity & 0.296 & 3.872 & $<0.001$ \\
Openness -> Interactivity & 0.516 & 5.285 & $<0.001$ \\
Openness -> Students' Achievement & 0.352 & 2.306 & 0.022 \\
Web 2.0 -> Autonomy & 0.973 & 222.46 & $<0.001$ \\
Web 2.0 -> Diversity & 0.526 & 7.209 & $<0.001$ \\
Web 2.0 -> Interactivity & 0.472 & 4.94 & $<0.001$ \\
Web 2.0 -> Openness & 0.970 & 201.802 & $<0.001$ \\
Web 2.0 -> Students' Achievement & 0.336 & 2.122 & 0.049 \\
\hline
\end{tabular}

As shown in Table 4, the study revealed that autonomy, diversity, interactivity, openness and Web 2.0 have a positive significant effect on students' achievement. Interactivity has a positive significant effect on diversity. Openness has a positive significant effect on diversity and interactivity. Web 2.0 has a positive significant effect on autonomy, diversity, interactivity and openness. In summary, all the latent variables are strongly correlated and hence showed the positive significant effect on the corresponding latent 


\section{CONCLUSION}

PLS-SEM is used to examine the determinants influencing students' achievement within matriculation college students through connectivism principles and Web 2.0 as a learning tool. A number of observations can be made from the analysis conducted on the structural model per se. The evaluation of the structural model demonstrated satisfactory results. The findings of this study provide important implications for students to employ Facebook as a platform in communicating and sharing knowledge. Administrators and faculty will be interested in the findings of this study as it gives better understanding on how to encourage IL among students. With this knowledge, administrators can understand: (i) the basis upon which students evaluate their level of satisfaction when using Facebook; (ii) how to promote diversity and autonomy, interactivity and openness towards IL and affect students' achievement.

The results of the study show that interactivity directly influence diversity towards students' achievement. [6] also points towards Facebook interactions affected students to foster a connection. This means that there are social driving forces in considering Facebook as an efficient way to accomplish a connection. Most educational institutions had come out with the idea of communicating with students in this way even though recent studies have revealed the problems that this activity can cause. This is in line with Flynn, Stansbury, and Young (2009) assertion that the use of social network needs to be involved in the social interactions of students and educators.

\section{ACKNOWLEDGEMENT}

The author would like to thank to the goverment of Malaysia.

\section{REFERENCES}

1. Chin, W.W. The partial least squares approach to structural equation modeling. In Marcoulides (ed.)Modern Methods for
Business Research. Mahwah: Lawrence Erlbaum Associates, 1998b.

2. Fein, M. L. Redefining higher education: How self-direction can save colleges. New Brunswick, NJ: Transaction, 2014.

3. Flynn, N. Facebook, take 2: Cyberbullying. Education week Retrieved from http://blogs.edweek.org/edweek/LeaderTalk/2009/05/facebook_ta ke_2_cyberbullying.html?qs=facebook, 2009.

4. Götz, O., Liehr-Gobbers, K., Krafft, M. Evaluation of structural equation models using the Partial Least Squares (PLS) approach. In Esposito Vinzi, V., Chin, W.W., Henseler, J., Wang, H. (eds.) Handbook of Partial Least Squares, pp. 691-711. Springer, Heidelberg, 2010.

5. Hair, J. F., Hult, G.T.M., Ringle, C.M., \& Sarstedt, M. A primer on structural equation modelling (PLS-SEM) ( $2^{\text {nd }}$ edition). Thousand Oaks, CA: Sage Publications, 2017.

6. Helvie-Mason, L. Facebook, "friending," and faculty-student communication. Teaching Arts and Science with the New Social Media, 3, 61-87, 2011.

7. Huber, F., Herrmann, A., Meyer, F., Vogel, J., \& Wollhardt, K.Kausalmodellierung mit Partial Least Squares-Eine anwendungsorientierte Einführung. Gabler, Wiesbaden, 2007.

8. Hyland, N., \& Kranzow, J. Faculty and student views of using digital tools to enhance self-directed learning and critical thinking. International Journal of Self-Directed Learning, 8(2), 11-27, 2011.

9. Kline, R. B. Principles and practice of structural equation modeling. New York, NY: Guilford Press, 2011.

10. Latan, H., \& Hoonan, R. (eds).p \Partial least squares path modeling: basic concepts, methodological issues and applications. Springer, Cham, Switzerland, 2017.

11. McWilliam, E.,\& Haukka, S.Educating the creative workforce: New directions for twenty-first century schooling. British Educational Research Journal, 34(5), 651-666, 2008.

12. Nitzl, C., \& Chin, W.W. The case of partial least squares (PLS) path modeling in managerial accounting. Journal of Management Control, 28(2), 137-156, 2017.

13. Orehovački, T., Granić, A., Kermek, D.Evaluating the perceived and estimated quality in use of Web 2.0 applications. Journal of Systems and Software, 86(12), 3039-3059, 2013.

14. Stansbury, M. Coach sued for requesting Facebook logins. eSchool News: Technology News for Today's K-20 Educator, November 20, 2009.

15. Tinmaz, H. Social networking websites as an innovative framework for connectivism. Contemporary Educational Technology, 3(3), 234-245, 2012.

16. Urbach, N., \& Ahlemann, F. Structural equation modeling in information systems research using Partial Least Square. Journal of Information Technology Theory and Application, 11(2), 5-40, 2010.

17. Young, J.R. How not to lose face on Facebook for professors. The Chronicle of Higher Education, February 6, 2009. 